\title{
Modestly increased beta cell apoptosis but no increased beta cell replication in recent-onset type 1 diabetic patients who died of diabetic ketoacidosis
}

\author{
A. E. Butler • R. Galasso - J. J. Meier • R. Basu • \\ R. A. Rizza - P. C. Butler
}

Received: 3 April 2007 / Accepted: 13 July 2007 / Published online: 6 September 2007

(C) Springer-Verlag 2007

\begin{abstract}
Aims/hypothesis Type 1 diabetes is characterised by a deficit in beta cell mass thought to be due to immunemediated increased beta cell apoptosis. Beta cell turnover has not been examined in the context of new-onset type 1 diabetes with diabetic ketoacidosis.

Methods Samples of pancreas were obtained at autopsy from nine patients, aged 12 to 38 years (mean $24.3 \pm 3.4$ years), who had had type 1 diabetes for less than 3 years before death due to diabetic ketoacidosis. Samples of pancreas obtained at autopsy from nine non-diabetic cases aged 11.5 to 38 years (mean $24.2 \pm 3.4$ years) were used as control. Fractional beta cell area (insulin staining), beta cell replication (insulin and Ki67 staining) and beta cell apoptosis (insulin and TUNEL staining) were measured.

Results In pancreas obtained at autopsy from recent-onset type 1 diabetes patients who had died of diabetic ketoacidosis, the beta cell deficit varied from 70 to $99 \%$ (mean 90\%). The pattern of beta cell loss was lobular, with almost all beta cells absent in most pancreatic lobules; islets in lobules not devoid of beta cells had reduced or a nearnormal complement of beta cells. Beta cell apoptosis was increased in recent-onset type 1 diabetes, but to a surprisingly modest degree given the marked hyperglycaemia (30 mmol/l), acidosis and presumably high NEFA. Beta
\end{abstract}

\footnotetext{
A. E. Butler • R. Galasso · J. J. Meier • P. C. Butler $(\bowtie)$

Larry Hillblom Islet Research Center,

UCLA David Geffen School of Medicine,

24-130 Warren Hall, 900 Veteran Avenue,

Los Angeles, CA 90095-7073, USA

e-mail: pbutler@mednet.ucla.edu

R. Basu $\cdot$ R. A. Rizza

Division of Endocrinology, Diabetes, Metabolism and Nutrition, Mayo Clinic,

Rochester, MN, USA
}

cell replication, scattered pancreatic beta cells and beta cells in exocrine ducts were not increased in recent-onset type 1 diabetes.

Conclusions/interpretation These findings do not support the notion of active beta cell regeneration by replication in new-onset type 1 diabetes under conditions of diabetic ketoacidosis. The gluco-lipotoxicity reported in isolated human islets may be less evident in vivo.

Keywords Apoptosis · Beta cell replication · Human . Islets · Islet degeneration and damage · Ketoacidosis .

Prediction of type 1 diabetes Prevention of type 1 diabetes . Recent-onset type 1 diabetes

\section{Abbreviation \\ IRB Institutional Review Board}

\section{Introduction}

Type 1 diabetes is characterised by hyperglycaemia due to insufficient insulin secretion. While it has become generally accepted that loss of insulin secretion in type 1 diabetes is due to autoimmune-mediated beta cell loss [1], the triggering mechanisms underlying the onset of the autoimmune process remain unknown. In addition, the mechanisms subserving beta cell loss in humans with type 1 diabetes are not well defined. Prior studies of type 1 diabetes of relatively recent onset in humans have reported a deficit in beta cell mass of about 70 to $100 \%$ [2-7], which declines to almost $100 \%$ in long-standing type 1 diabetes [2-4, 8, 9]. We have reported that most patients with longstanding type 1 diabetes had some detectable beta cells [9]. Since these beta cells were associated with a low-grade 
lymphocytic infiltrate and had increased beta cell apoptosis, we hypothesised that ongoing beta cell turnover is present in patients with long-standing type 1 diabetes [9], implying a continuous source of new beta cells.

Susbsequently we had the opportunity to examine a sample of pancreas from a patient with new-onset type 1 diabetes: an 89-year-old man who had a partial pancreatectomy for a low-grade pancreatic intraepithelial neoplasia [10]. In this case, as expected, beta cell apoptosis was increased, but surprisingly beta cell replication was also markedly increased compared with that in non-diabetic adult humans. However, it is not known whether the increased beta cell replication observed in this case was typical of new-onset type 1 diabetes. In order to address this, we examined pancreatic tissue obtained at autopsy from nine patients who died of diabetic ketoacidosis within 3 years of onset of diabetes. The fact that these pancreases were from patients with diabetic ketoacidosis is an inevitable limitation of this study, since pancreas samples from young people with recent-onset type 1 diabetes are rarely available otherwise. We quantified pancreatic fractional beta cell area, beta cell replication and beta cell apoptosis in these recent-onset cases of type 1 diabetes and in case-controlled non-diabetic samples. For comparison we also used tissue from the previously reported 89-year-old patient with recent-onset type 1 diabetes [10].

\section{Methods}

Autopsy cases Human pancreatic tissue was obtained from autopsy archival paraffin blocks from nine individuals with type 1 diabetes (three male, six female, aged 12-38 years, mean age $24.3 \pm 3.4$ years). We obtained Mayo Clinic Institutional Review Board (IRB) approval. Potential cases were identified by retrospective analysis of the Mayo Clinic autopsy database. These cases of type 1 diabetes were identified from autopsy archives dating from the 1930s and 1940s; in more recent years, diabetic ketoacidosis is more readily diagnosed and treated, so fortunately such patients now rarely come to autopsy. To be included, cases were required to: (1) have had a full autopsy within $24 \mathrm{~h}$ of death; (2) have pancreatic tissue samples of adequate size and quality; and (3) have been diagnosed with type 1 diabetes. Pancreas samples were formalin-fixed for $24 \mathrm{~h}$ and then paraffin-embedded. Sections of formalin-fixed, paraffinembedded spleen from each case were also obtained: these served as an internal control for replication and apoptosis. Cases were excluded if pancreatic tissue had undergone autolysis or showed evidence of acute pancreatitis. As a positive control for increased beta cell replication, we studied newly sectioned pancreas samples from the surgical pancreatectomy of an 89-year-old man with new-onset type 1 diabetes (previously reported in [10]). In this case, written informed consent was obtained from the patient in compliance with the University of California, Los Angeles (UCLA) IRB guidelines.

For non-diabetic controls, IRB approval from the Mayo Clinic was obtained and human pancreas tissue from nine individuals was obtained from autopsy archival blocks. The archival tissue dated from the 1980s and 1990s. Inclusion criteria were the same as for the type 1 diabetes cases, with the exception that they were non-diabetic. Exclusion criteria were identical to those for type 1 diabetes. Sections of spleen were also available in control cases, serving as an internal control. However, the nine control tissues were from patients who had died several decades later than the diabetic cases. To ensure that the storage time of the autopsy tissue had not affected the detection of Ki67 and TUNEL staining, we studied spleen tissue, which has a known high frequency of replication and apoptosis. Sections from spleen of four non-diabetic autopsy cases dating from the 1930s were obtained and stained in parallel with spleen from the type 1 diabetes cases dating from the 1930 s to 1940 s and that from the controls dating from the 1980 s to 1990 s, using exactly the same protocol as described for pancreas. The frequency of replication (by Ki67) and apoptosis (by TUNEL) was evaluated in those sections in 20 high-power $(\times 400)$ fields per case. The frequency of Ki67-positive cells per 20 high-power fields was $42 \pm 4,66 \pm 3,30 \pm 4$ in the type 1 diabetes cases (1930s), controls (1930s) and controls (1980s), respectively. The frequency of TUNEL-positive cells per 20 highpower fields was $39 \pm 3,38 \pm 4$ and $35 \pm 3$ for the same groups, respectively. We concluded from these data that no loss of antigenicity for Ki67 or TUNEL had occurred in the paraffin-embedded sections from 1930 to 1990 .

Pancreatic tissue processing Pancreas tissue was fixed in formaldehyde and embedded in paraffin for subsequent analysis as previously described $[9,10]$. Sequential $5 \mu \mathrm{m}$ sections were stained as follows: (1) insulin (peroxidase staining) and haematoxylin for light microscopy; (2) insulin and TUNEL combined (peroxidase staining); (3) insulin, Ki67 and DAPI combined (immunofluorescence); and (4) insulin, glucagon and CD3 combined (immunofluorescence).

For immunohistochemistry the following primary antibodies were used: guinea pig anti-insulin, 1:100 (Zymed Laboratories, San Francisco, CA, USA); mouse antiglucagon, 1:2000 (Dako, Carpenteria, CA, USA); mouse Ki67, 1:200 (MIB-1; Dako); rabbit anti-CD3, 1:50 (Dako). Secondary antibodies labelled with Cy3, FITC and 7-amino 4-methylcoumarin 3-acetic acid (AMCA) were obtained from Jackson Laboratories (Jackson ImmunoResearch 
Laboratories, West Grove, PA, USA) and used at dilutions of 1:100 to 1:200. For TUNEL staining, an in situ cell death detection kit (KIT AP; Roche Diagnostics, Indianapolis, IN, USA) was used.

Morphometric analysis For determination of the fractional beta cell area, the entire pancreatic section was imaged at $\times 40$ magnification ( $\times 4$ objective). The ratio of the beta cell area: exocrine area was digitally quantified as previously described $[9,10]$ using Image Pro Plus software (Media Cybernetics, Silver Springs, MD, USA).

To determine beta cell replication, sections of pancreas double-stained for insulin and Ki67 by immunofluorescence were examined; all islets in the section were examined and the number of Ki67-positive cells expressed in terms of cells per islet as well as in relation to the respective beta cell area. One section of pancreas from each of the diabetic and control cases was available; for the 89year-old man, sections from four blocks were available and the mean values of the data from the four sections were calculated. To determine the extent of replicating cells associated with exocrine ducts and endothelial cells, ten random locations in each section stained by immunofluorescence for insulin, Ki67 and DAPI were imaged at $\times 200$ magnification $(\times 20$ objective) and analysed in detail. The total number of Ki67-positive cells per section, as well as the number of beta cells co-staining with Ki67, was quantified. The number of replicating beta cells was expressed as a percentage of the total number of beta cells per case. For determination of apoptosis, we used slides double-stained for insulin and TUNEL by immunoperoxidase and analysed 100 islets per case. The number of apoptotic beta cells was expressed in terms of cells per islet as well as in relation to the respective beta cell area. One section from each of the diabetic and control cases and four sections from the 89-year-old man were available. For determination of the extent of beta cells associated with exocrine ducts, we examined sections of pancreas that had been stained for insulin by immunohistochemistry for light microscopy and counterstained with haematoxylin; the total number of cells comprising 60 exocrine ducts was counted in each case and the number of insulin-positive duct cells was expressed as a percentage of the total number of duct cells. The number of scattered individual insulin-positive cells was determined on the same insulin-stained sections; the number of individual insulin-positive cells in the entire pancreas section was counted. The size of the pancreatic tissue section in $\mathrm{mm}^{2}$ was determined using Image Pro Plus software and the number of individual insulin-positive cells was expressed as number per $\mathrm{mm}^{2}$ pancreatic tissue.

For the determination of islet size, pancreatic sections stained for insulin (peroxidase) and haematoxylin were analysed. After careful assessment of the entire pancreatic section, ten representative islets were identified. For each islet, we first measured the total islet size using Image Pro Plus software (Media Cybernetics) and then measured the insulin-positive area of each islet. Islet density was quantified by measuring the total area of the pancreas section using Image Pro Plus software (Media Cybernetics) and counting the number of islets contained within that pancreatic area. An islet was defined as a cluster of four or more insulin-positive cells.

Statistical analysis Data are presented as mean \pm SEM. For statistical comparisons we used a two-sided unpaired Student's $t$ test with a $p$ value of less than 0.05 taken as significant.

\section{Results}

Pancreas morphology Figure 1 shows that, as previously reported, the beta cell deficit, both between cases of recentonset type 1 diabetes and between lobules within cases, was heterogeneous. In most pancreatic lobules, islets were almost completely devoid of beta cells as defined by insulin staining. By contrast, in lobules not devoid of beta cells we found that beta cells were present in most islets. In islets with insulin-positive cells, the complement of beta cells ranged from only a few per islet to a near-normal complement (Fig. 1). Where beta cells were present, some (but not all) within an islet had the appearance previously referred to as hydrops (intracellular regions that do not stain for insulin and that may have contained glycogen prior to fixation) [11]. Heterogeneity was also seen with regard to infiltration of islets with lymphocytes (Table 1). In the available sections studied, lymphocytic infiltrate in a proportion of islets was found in five of the nine cases (Fig. 1). However, in four of the nine cases no lymphocytic infiltrate was detected. In cases with an infiltrate, this tended to be present in a lobular pattern, as previously described [12]. Some prior reports of new-onset type 1 diabetes have noted occasional enlarged islets and indeed we, too, observed a greater range in the cross-sectional area of islets with insulin-positive cells in type 1 diabetes than in control tissue (140-68,730 $\mathrm{mm}^{2}$ for type 1 diabetes cases vs 1,254 $54,564 \mu^{2}$ for controls). When the overall fraction of pancreas occupied by insulin-positive cells was compared, the extent of the deficit in type 1 diabetes cases vs controls $(0.17 \pm 0.06$ vs $2.04 \pm 0.21 \%, p<0.01)$ varied from 75 to $99 \%$ (mean 90\%) (Fig. 2a). In the type 1 diabetes cases there was no relationship between the fractional beta cell area and either blood glucose at the time of death $(r=0.06)$, age at death $(r=0.1)$ or time since diabetes onset $(r=0.09)$. 


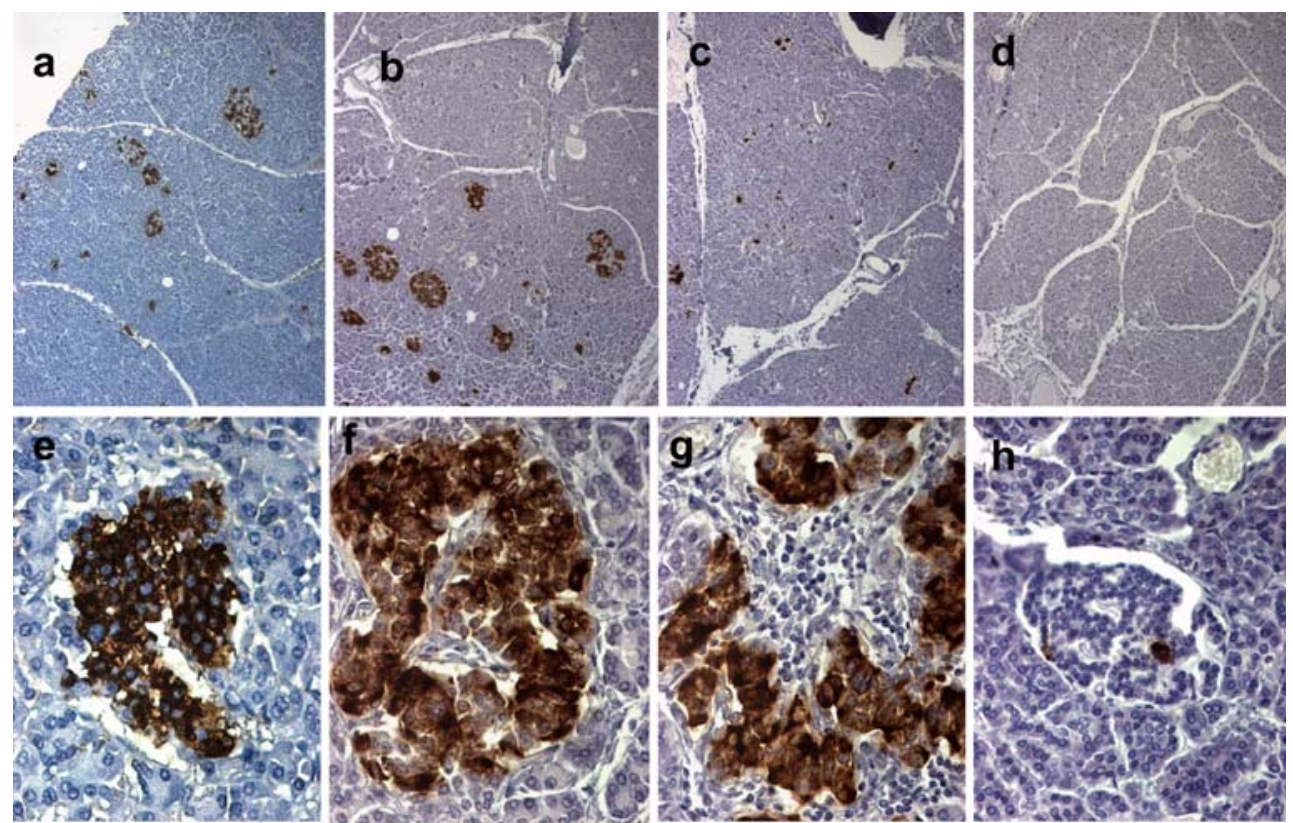

Fig. 1 Sections of pancreas stained for insulin and haematoxylin. a Low-power image of control non-diabetic pancreas, demonstrating normal distribution of islets within exocrine pancreas tissue. e Highpower image of a normal islet from a control non-diabetic tissue section. $\mathbf{b}-\mathbf{d}, \mathbf{f}-\mathbf{h}$ Images from pancreas of recent-onset type 1 diabetes cases with $\mathbf{b}$ normal islet distribution in one lobe of pancreas occurring adjacent to a lobe of pancreas with no insulin-containing islets, $\mathbf{c}$ a

Beta cell apoptosis As shown in Figs 3 and 4, the frequency of beta cell apoptosis was increased in the type 1 diabetes cases relative to controls $(0.25 \pm 0.06$ vs $0.004 \pm 0.00$ apoptotic cells per islet). There was no significant relationship between the frequency of beta cell apoptosis and either the blood glucose concentration at death, the presence of lymphocytic infiltrate within islets or the age at death. We reconfirmed an increased frequency of beta cell apoptosis compared with non-diabetic control tissue in the pancreas from the previously reported 89 -year-old man.

Beta cell replication In the sample of pancreas from the 89year-old man we also reconfirmed (Figs 3 and 4) an increased frequency of beta cell replication compared with nondiabetic control tissue. The tissue from the 89-year-old man served as a positive control for beta cell replication run in parallel with the sections from the new-onset type 1 diabetic case and non-diabetic control tissue obtained at autopsy in the present study. Beta cell replication was not increased in the nine recent-onset cases of type 1 diabetes with diabetic ketoacidosis (Figs 3 and 4). To further ensure that the Ki67 technique was valid in these cases, we also evaluated the frequency of Ki67-staining in vascular endothelium in all cases. The frequency of cells in the vascular endothelium that were positive for Ki67 in tissue from the new-onset cases of type 1 diabetes was slightly, but not statistically diminished number of beta cells, with insulin-positive cells occurring individually or in small clusters, $\mathbf{d}$ pancreas lobules lacking any insulin-positive cells, $\mathbf{f}$ a relatively normal islet, $\mathbf{g}$ an islet with an inflammatory infiltrate and $\mathbf{h}$ the most typical islets in this group, which are almost devoid of beta cells and have no inflammatory infiltrate. Magnification: a-d low power $(\times 40)$; $\mathbf{e}-\mathbf{h}$ high power $(\times 400)$

significantly less than that in the non-diabetic control tissues (0.34 \pm 0.23 vs $0.88 \pm 0.25 \%)$ (Fig. 5).

Insulin-positive cells in ducts and scattered insulin-positive cells Scattered insulin-positive cells in pancreas and the percentage of insulin-positive cells in exocrine ducts have previously been considered possible markers of newly forming beta cells from pancreatic progenitor cells, although this approach has not been validated. In tissue from cases of recent-onset type 1 diabetes, there was a marked reduction in the number of insulin-positive cells in exocrine pancreatic ducts, with none seen compared with controls $(0.00 \pm 0.00$ vs $1.01 \pm 0.14 \%)$ (Fig. 2c). Similarly, there was a reduction in the frequency of individual insulinpositive cells scattered throughout the exocrine pancreas (type 1 diabetes cases $0.21 \pm 0.07$ vs control $1.13 \pm 0.17$ cells $/ \mathrm{mm}^{2}, p<0.0001$ ) (Fig. 2b).

Lymphocytic infiltrate An additional section of pancreas from each case was stained for insulin, glucagon and CD3 antibody to determine the presence or absence of a lymphocytic infiltrate. A lymphocytic infiltrate was defined as the presence of three or more CD3-positive cells within or immediately adjacent to an islet. A lymphocytic infiltrate was detected in the available sections in five of the nine samples from type 1 diabetes cases (Table 1, Fig. 6) and in 


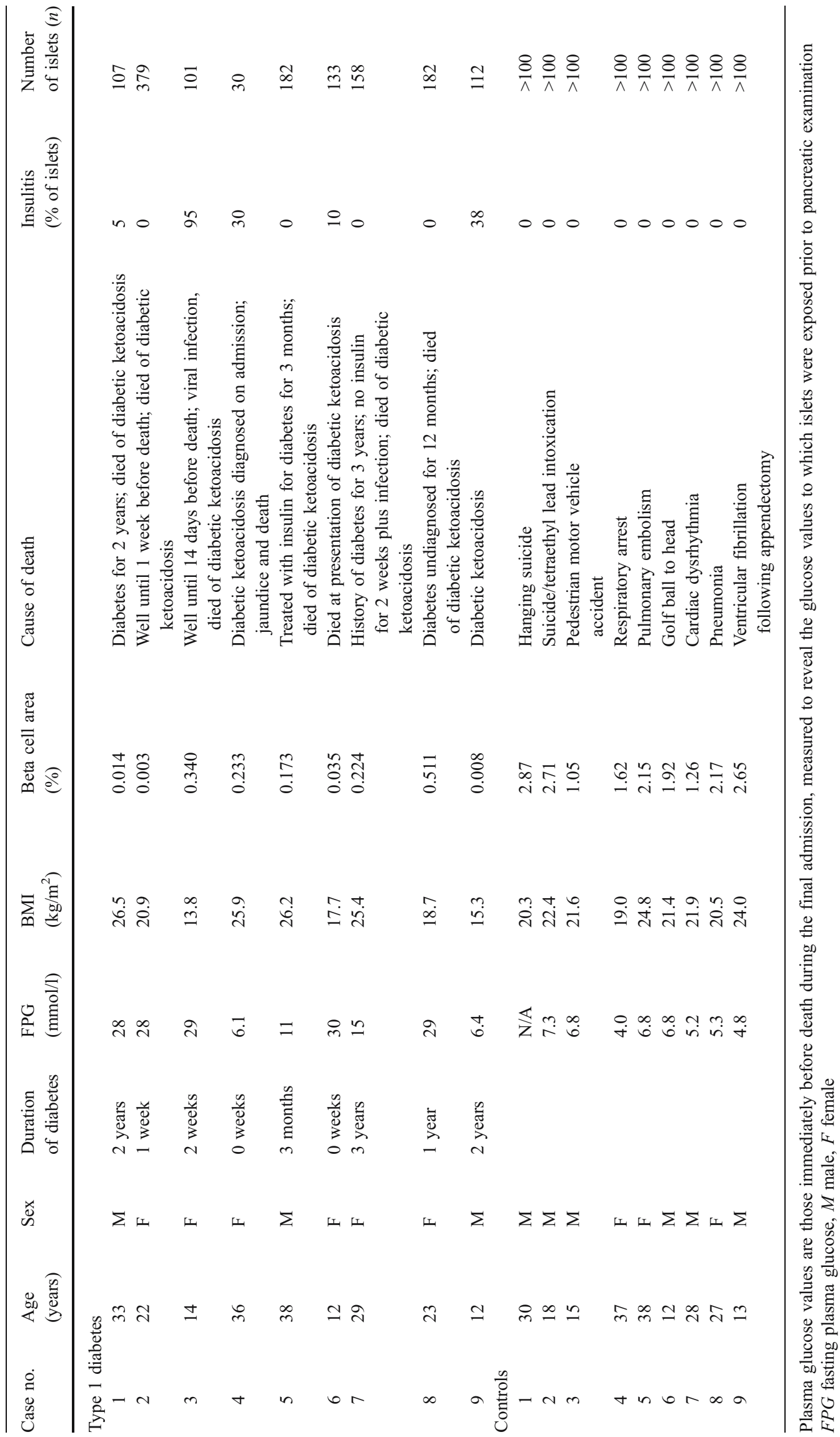


a

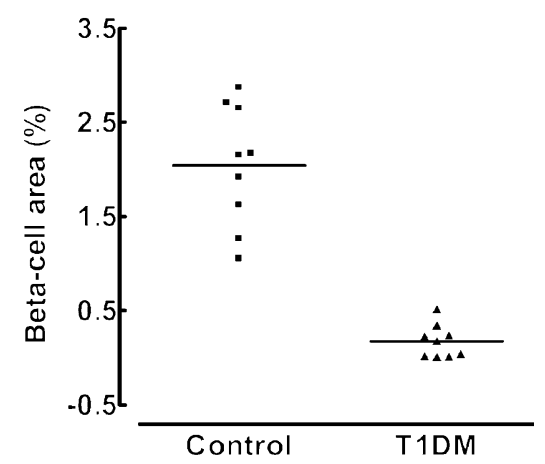

b

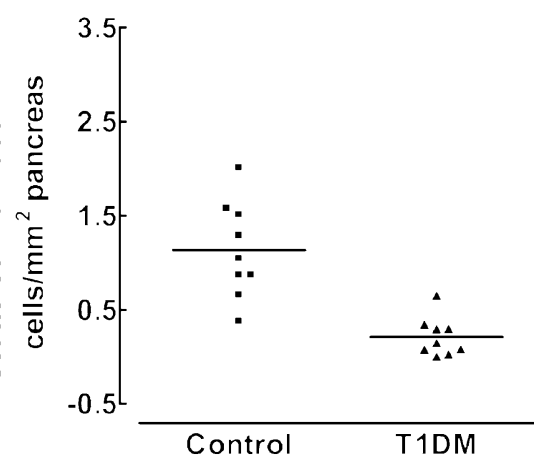

C

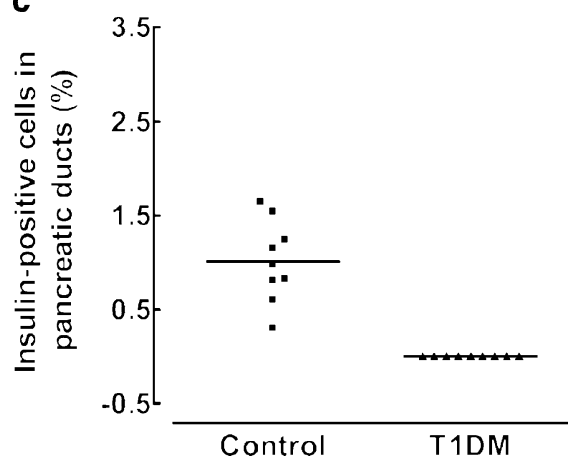

Fig. 2 a Beta cell area as a percentage of total pancreas area in samples from nine age-matched non-diabetic controls and nine cases with recent-onset type 1 diabetes. b Number of scattered individual beta cells per $\mathrm{mm}^{2}$ of pancreas in the same cases and controls. $\mathbf{c}$ Percentage of insulin-positive cells present in exocrine pancreatic ducts. $p<0.0001$ for all panels. T1DM, type 1 diabetes mellitus

all type 1 diabetes cases aged $<20$ years. The presence or absence of a detected lymphocytic infiltrate was more variable in cases of type 1 diabetes aged $>20$ years. In positive cases, there was a wide variation in the percentage of affected islets, ranging from 5 to $95 \%$; islets with infiltration tended to follow a lobular distribution.

\section{Discussion}

In this study we studied pancreas tissue from patients with type 1 diabetes who had died from diabetic ketoacidosis and whose diagnosis of diabetes had been made less than
3 years before death. We quantified the beta cell deficit and examined beta cell turnover in these pancreases.

Prior studies have reported a similar range of beta cell deficit in patients with new-onset type 1 diabetes [2-7]. It might be anticipated that patients with diabetic ketoacidosis leading to death would have a lower residual beta cell mass than most newly presenting cases of type 1 diabetes. Indeed insulin secretion in people with treated recent-onset type 1 diabetes suggests a relatively preserved beta cell function and therefore presumably beta cell mass $[13,14]$. It is perhaps surprising that individuals with as much as $30 \%$ of the normal beta cell complement should have died of diabetic ketoacidosis, given the conventional teaching that this occurs as a consequence of almost complete insulin deficiency. The most likely explanation is that not only does new-onset type 1 diabetes result from a deficit in beta cells, but also from a profound deficit in beta cell function. This postulate gains support from the partial recovery of insulin secretion and glucose homeostasis (the so-called 'honeymoon period') observed in many patients after insulin therapy is initiated for type 1 diabetes $[15,16]$. A similar situation has recently been recognised in type 2 diabetes, where diabetic ketoacidosis is an increasingly recognised complication, particularly in African-American and Hispanic patients. Again, many of these patients no longer need insulin therapy once treated [17, 18]. Collectively these data emphasise the complex relationship between beta cell mass, beta cell function and insulin sensitivity. In the setting of a normal beta cell mass, insulin resistance does not lead to hyperglycaemia or subsequent metabolic decompensation to diabetic ketoacidosis. However, once beta cell mass declines to approximately $50 \%$ of normal, impaired fasting glucose and glucose intolerance may develop $[19,20]$. With each further decrement in beta cell mass, there appears to be a much more marked increase in blood glucose, implying an adverse interaction between declining beta cell mass, impaired beta cell function and increasing insulin resistance [20]. The present study suggests that a deficit in beta cell mass of $70 \%$ or more in the context of the adverse beta cell environment present in type 1 diabetes is sufficient to lead to diabetic ketoacidosis.

The mechanisms subserving loss of beta cells in type 1 diabetes remain unclear. While there is little doubt that there is an autoimmune basis for type 1 diabetes, the trigger (s) that promote this cycle of autoimmunity remain unknown. Consistent with some prior reports, we noted a lobular distribution of beta cell loss and a tendency for a more readily detectable lymphocytic infiltrate in patients with a younger age of onset $(100 \%$ of patients $<20$ years old vs $30 \%$ of those $>20$ years old at onset) $[2-4,6,7]$. Some lobules were characterised by islets that were almost completely devoid of beta cells, yet were adjacent to lobules containing islets with a near-normal complement 

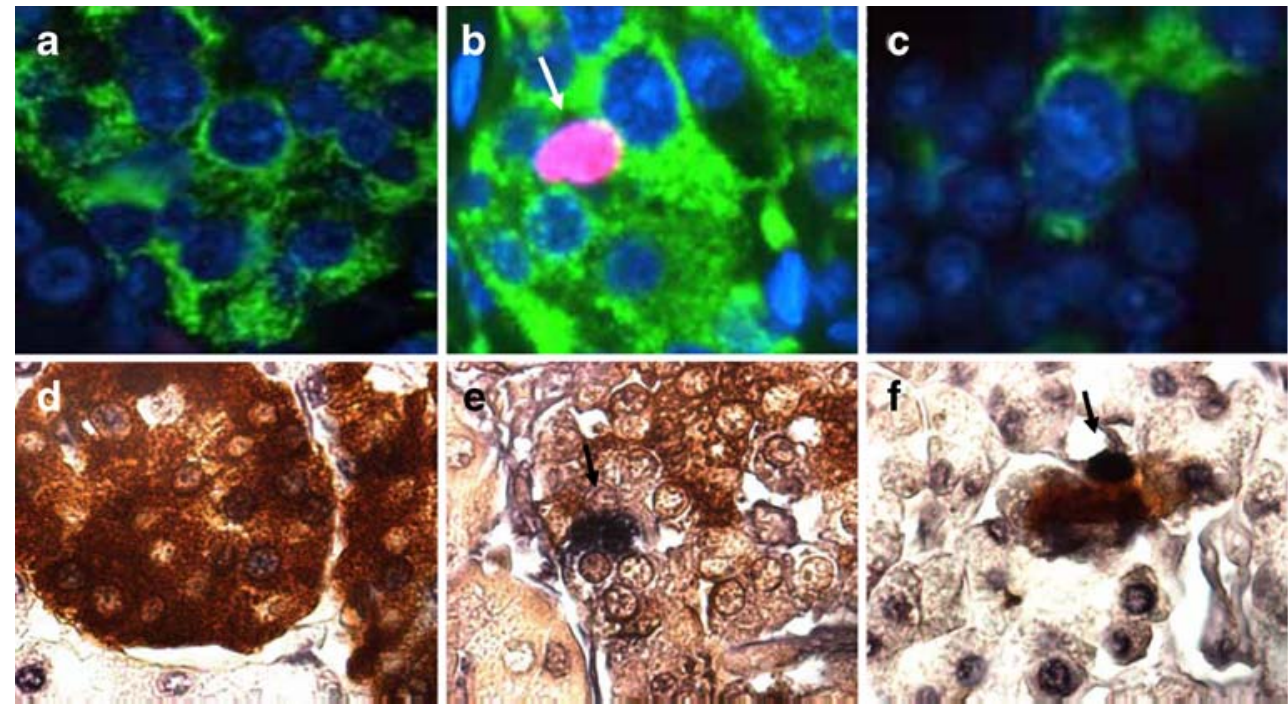

Fig. 3 a-c Tissue stained by immunofluorescence for insulin (green), Ki67 (red) and DAPI (blue). a A normal islet from a control pancreas; b section from the pancreas of the 89 -year-old patient who had recentonset type 1 diabetes and underwent partial pancreatectomy for a pancreatic tumour. Arrow, Ki67-positive nucleus in a beta cell. c Two islets from a case of recent-onset type 1 diabetes. Islets are devoid of any Ki67-positive nuclei. d-f Tissue stained by immunohistochemistry for TUNEL (purple/black) and insulin (brown). d A control islet lacking TUNEL-positive nuclei; e a doublet of apoptotic beta cells in an islet (arrow), indicative of post-mitotic apoptosis in the 89-year-old patient. f An apoptotic nucleus (arrow) in an islet from a patient with recent-onset type 1 diabetes. Photographed at: $\mathbf{a}-\mathbf{c} \times 20 ; \mathbf{d}-\mathbf{f} \times 100$ of beta cells. Indeed most islets in these new-onset cases of type 1 diabetes could be subdivided into those with no detectable beta cells (approximately 80-90\%) and those with a normal complement of beta cells (approximately 10-20\%). This implies that the loss of beta cells is analogous to that in vitiligo, with a near-complete loss in some lobules and minimal loss in other lobules, rather than a general loss throughout the pancreas. Such a mechanism is consistent with an autoimmune model with islets upstream of activated lymph nodes vulnerable to accelerated beta cell loss.

Perhaps the most surprising finding in the present study is the relatively modest increase in frequency of beta cell apoptosis in the islets with a near-normal complement of beta cells. While this is consistent with the notion of a regional autoimmune process, the relatively low frequency of beta cell apoptosis is a testament to the effectiveness of the beta cell anti-apoptotic mechanisms in vivo compared with those in isolated human islets. Isolated human islets exposed to a glucose concentration of $30 \mathrm{mmol} / 1$ [21, 22] or a fatty acid concentration of more than $2 \mathrm{mmol} / \mathrm{l}$ [23] have a marked increase in beta cell apoptosis. In these patients with diabetic ketoacidosis, the beta cells within the islets with a near-normal complement of beta cells were exposed to marked hyperglycaemia ( $30 \mathrm{mmol} / \mathrm{l})$ and (presumably) to NEFA concentrations in excess of $2 \mathrm{mmol} / \mathrm{l}$. Moreover, these islets were exposed to the acidosis present in diabetic ketoacidosis. These data serve to support caution when extrapolating findings, such of those on gluco-lipotoxicity carried out in isolated islets $[21,22]$, to the in vivo situation, where the beta cell anti-apoptosis mechanisms appear to be much more effective than in isolated islets.

A primary goal of the present studies was to evaluate the frequency of beta cell replication in new-onset type 1 diabetes. Beta cell replication was not increased in these cases of recent-onset type 1 diabetes complicated by diabetic ketoacidosis. This finding is in contrast to those in pancreas samples obtained surgically from an 89-year-old man with recent-onset type 1 diabetes, which are reconfirmed here in newly sectioned slides studied in parallel with tissue from recent-onset cases with diabetic ketoacidosis [10].

There are several possible explanations for this discrepancy. The pancreatic intraepithelial tumour in the 89-yearold man could have theoretically expressed a factor or factors that promoted beta cell replication. Although we cannot rule it out, this explanation seems unlikely, given that the frequency of beta cell replication in this case was not related to distance from the pancreatic tumour (in contrast to the situation in human gastrinomas [24]). Another possibility is that the capacity for beta cell replication in response to beta cell destruction in type 1 diabetes in the elderly is different from that in younger patients. At present we have insufficient data to address that possibility, although in general attempted tissue regeneration through cell replication would not be expected to be more prominent in elderly than in younger patients. While controversial, it is thought that onset of type 1 diabetes in the older population may be a different disease from that with onset in younger individuals [25]. 
a

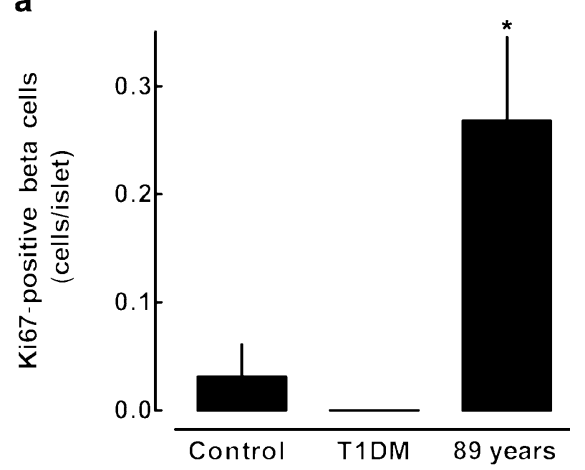

b

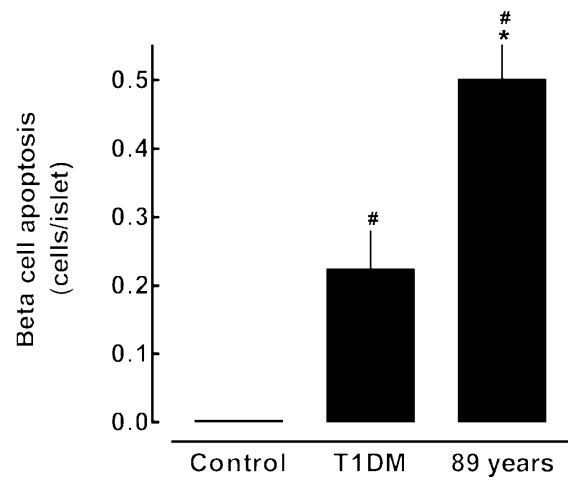

Fig. 4 a Number of Ki67-positive beta cells, expressed as cells per islet, in pancreas samples from nine age-matched non-diabetic controls and nine cases with recent-onset type 1 diabetes, as well as in an 89-year-old man with new-onset type 1 diabetes and a pancreatic tumour. b Number of TUNEL-positive beta cells, expressed as cells per islet, in the same samples. ${ }^{*} p<0.05$ for 89 -year-old man vs type 1 diabetes; $\# p<0.001$ for 89 -year-old man vs control and for type 1 diabetes vs control. T1DM, type 1 diabetes mellitus

Perhaps the most likely explanation for the difference in beta cell replication between the people with recent-onset type 1 diabetes who died of diabetic ketoacidosis and the previously reported surgical case is the deleterious consequences of the ketoacidosis. In support of this, we note that there was a modest decrease in beta cell replication in the pancreatic endothelial cells from new-onset type 1 diabetes cases vs those from controls. Beta cells are particularly prone to oxidative stress [26], which is induced by high glucose concentrations and acidosis. Cell cycle progression is dependent on normal ion channel function [27], which is compromised in acidosis. In culture, cell replication is decreased under conditions of acidosis. Therefore, while it is impossible to know with certainty why beta cell replication was if anything decreased in the new-onset type 1 diabetes cases (vs non-diabetic controls) and was certainly decreased in comparison with the 89year-old man with new-onset type 1 diabetes and partial pancreatectomy, suppression of adaptive beta cell replication by diabetic ketoacidosis is a plausible explanation.

The conclusions of the present study have therefore to be tempered to acknowledge that while we report no evidence of increased beta cell replication in recent-onset type 1

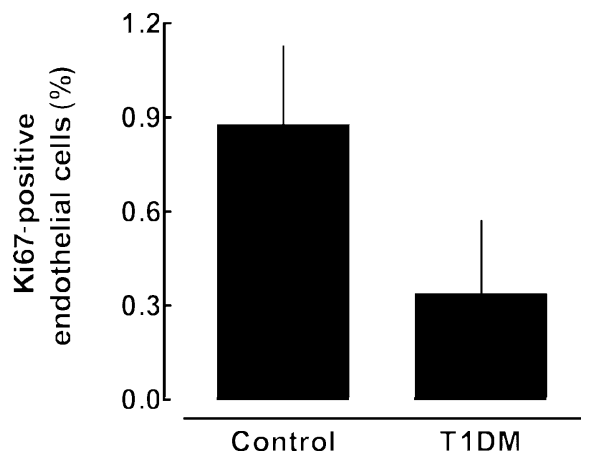

Fig. 5 The percentage of Ki67-positive endothelial cells in pancreas samples from nine age-matched non-diabetic controls and nine cases with recent-onset type 1 diabetes. While the percentage of Ki67positive endothelial cells was lower in sections of pancreas from type 1 diabetes cases, this did not reach statistical significance

diabetes after death due to diabetic ketacidosis, this may not reflect the status in these patients prior to the onset of metabolic decompensation. Indeed, in a recent report, pancreas tissue procured from non-diabetic brain-dead donors who were positive for islet autoantibodies revealed occasional islets with lymphocytic infiltration and increased beta cell replication [12]. These intriguing findings are consistent with the postulate that low levels of proinflammatory cytokines may foster beta cell replication rather than beta cell apoptosis [28]. The findings of others [2], confirmed here, of greater heterogeneity in islet size, most notably with some markedly enlarged islets in newonset type 1 diabetes, are also consistent with prior efforts at beta cell regeneration through increased intra-islet beta cell replication eventually being overcome by increased beta cell destruction.

In summary, pancreas tissue in humans with recent-onset type 1 diabetes who died of diabetic ketoacidosis reveals a lobular pattern of beta cell loss, with most islets containing

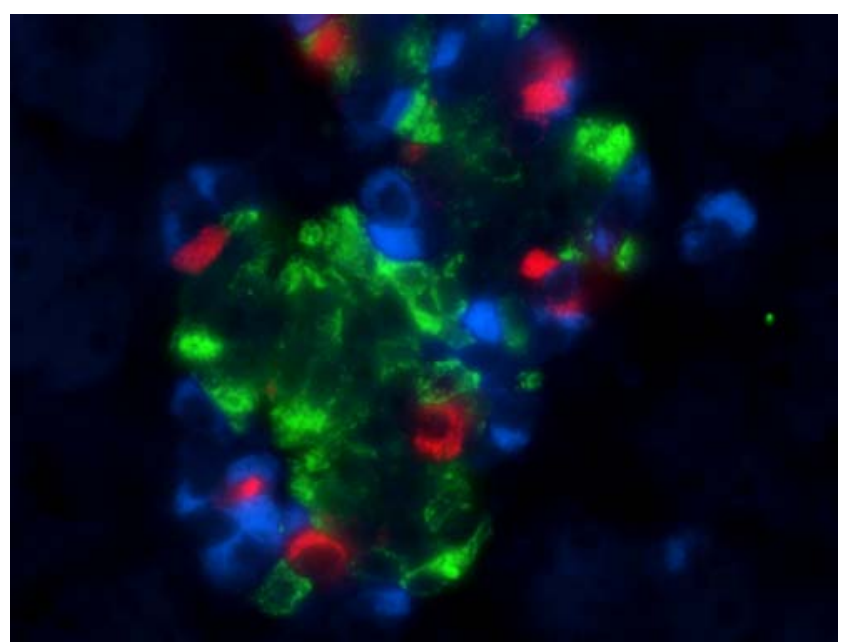

Fig. 6 An islet from a woman with recent-onset type 1 diabetes (age 36 years; case number 4 in Table 1). The image shows a CD3-positive inflammatory infiltrate within an islet. CD3, red; glucagon, blue; insulin, green. Photographed at: $\times 400$ 
no detectable beta cells and those not devoid of beta cells having an apparently normal complement of beta cells. The deficit in beta cells in these cases varied from $\sim 70$ to $99 \%$, with a modestly increased frequency of beta cell apoptosis in the remaining beta cells despite markedly increased blood glucose (and presumably NEFA) and acidosis. In these pancreases, which were procured after death from ketoacidosis, beta cell replication was not increased and scattered pancreatic beta cells and beta cells within exocrine ducts were decreased compared with non-diabetic control tissue.

Acknowledgements The present studies were funded by the Larry Hillblom Foundation and the Juvenile Diabetes Research Foundation. We acknowledge the excellent suggestions from our colleagues at the Larry Hillblom Islet Research Center, specifically A. Bhushan, L. Haataja, T. Gurlo and K. Maedler. We are particularly indebted to B. Lui for administrative support.

Duality of interest The authors declare that there is no duality of interest associated with this manuscript.

\section{References}

1. Atkinson MA, Eisenbarth GS (2001) Type 1 diabetes: new perspectives on disease pathogenesis and treatment. Lancet 358:221-229

2. Gepts W (1965) Pathologic anatomy of the pancreas in juvenile diabetes mellitus. Diabetes 14:619-633

3. Junker K, Egeberg J, Kromann H et al (1977) An autopsy study of the islets of Langerhans in acute-onset juvenile diabetes mellitus. Acta Pathol Microbiol Scand A 85:699-706

4. Gepts W, De Mey J (1978) Islet cell survival determined by morphology. An immunocytochemical study of the islets of Langerhans in juvenile diabetes mellitus. Diabetes 27(Suppl 1):251-261

5. Kloppel G, Drenck CR, Oberholzer M et al (1984) Morphometric evidence for a striking B-cell reduction at the clinical onset of type 1 diabetes. Virchows Arch A Pathol Anat Histopathol 403:441-452

6. Foulis AK, Stewart JA (1984) The pancreas in recent-onset type 1 (insulin-dependent) diabetes mellitus: insulin content of islets, insulitis and associated changes in the exocrine acinar tissue. Diabetologia 26:456-461

7. Lernmark A, Kloppel G, Stenger D et al (1995) Heterogeneity of islet pathology in two infants with recent onset diabetes mellitus. Virchows Arch 425:631-640

8. Lohr M, Kloppel G (1987) Residual insulin positivity and pancreatic atrophy in relation to duration of chronic type 1 (insulin-dependent) diabetes mellitus and microangiopathy. Diabetologia 30:757-762

9. Meier JJ, Bhushan A, Butler AE et al (2005) Sustained beta cell apoptosis in patients with long-standing type 1 diabetes: indirect evidence for islet regeneration? Diabetologia 48:2221-2228
10. Meier JJ, Lin JC, Butler AE et al (2006) Direct evidence of attempted beta cell regeneration in an 89-year-old patient with recent-onset type 1 diabetes. Diabetologia 49:1838-1844

11. Allen FM (1922) Hydropic degeneration of islands of Langerhans after partial pancretectomy. J Metab Res 1:5-41

12. In't Veld P, Lievens D, De Grijse J et al (2007) Screening for insulitis in adult autoantibody-positive organ donors. Diabetes DOI 10.2337/db07-0416

13. Palmer JP, Fleming GA, Greenbaum CJ et al (2004) C-peptide is the appropriate outcome measure for type 1 diabetes clinical trials to preserve beta-cell function: report of an ADA workshop, 21-22 October 2001. Diabetes 53:250-264

14. Tsai EB, Sherry NA, Palmer JP et al (2006) The rise and fall of insulin secretion in type 1 diabetes mellitus. Diabetologia 49:261-270

15. Hramiak IM, Dupre J, Finegood DT (1993) Determinants of clinical remission in recent-onset IDDM. Diabetes Care 16:125-132

16. Karges B, Durinovic-Bello I, Heinze E et al (2004) Complete long-term recovery of beta-cell function in autoimmune type 1 diabetes after insulin treatment. Diabetes Care 27:1207-1208

17. Rasouli N, Elbein SC (2004) Improved glycemic control in subjects with atypical diabetes results from restored insulin secretion, but not improved insulin sensitivity. J Clin Endocrinol Metab 89:6331-6335

18. Kumar D, Luna-Lollie T, Madha S (2001) One-hour meal tolerance test to assess withdrawal of insulin therapy in overweight patients with type 2 diabetes. Endocr Pract 7:256-261

19. Matveyenko AV, Veldhuis JD, Butler PC (2006) Mechanisms of impaired fasting glucose and glucose intolerance induced by an approximate 50\% pancreatectomy. Diabetes 55:2347-2356

20. Ritzel RA, Butler AE, Rizza RA et al (2006) Relationship between beta-cell mass and fasting blood glucose concentration in humans. Diabetes Care 29:717-718

21. Federici M, Hribal M, Perego L et al (2001) High glucose causes apoptosis in cultured human pancreatic islets of Langerhans: a potential role for regulation of specific Bcl family genes toward an apoptotic cell death program. Diabetes 50:1290-1301

22. Maedler K, Sergeev P, Ris F et al (2002) Glucose-induced beta cell production of IL-1beta contributes to glucotoxicity in human pancreatic islets. J Clin Invest 110:851-860

23. Lupi R, Dotta F, Marselli L et al (2002) Prolonged exposure to free fatty acids has cytostatic and pro-apoptotic effects on human pancreatic islets: evidence that beta-cell death is caspase mediated, partially dependent on ceramide pathway, and $\mathrm{Bcl}-2$ regulated. Diabetes 51:1437-1442

24. Meier JJ, Butler AE, Galasso R et al (2006) Increased islet beta cell replication adjacent to intrapancreatic gastrinomas in humans. Diabetologia 49:2689-2696

25. Stenstrom G, Gottsater A, Bakhtadze E et al (2005) Latent autoimmune diabetes in adults: definition, prevalence, beta-cell function, and treatment. Diabetes 54(Suppl 2):S68-S72

26. Robertson RP, Harmon JS (2006) Diabetes, glucose toxicity, and oxidative stress: a case of double jeopardy for the pancreatic islet beta cell. Free Radic Biol Med 41:177-184

27. Kahl CR, Means AR (2003) Regulation of cell cycle progression by calcium/calmodulin-dependent pathways. Endocr Rev 24:719-736

28. Donath MY, Ehses JA, Maedler K et al (2005) Mechanisms of betacell death in type 2 diabetes. Diabetes 54(Suppl 2):S108-S113 